\title{
CARACTERIZAÇÃO MICROBIOLÓGICA E FÍSICO-QUÍMICA DE RICOTA PRODUZIDA EM UMA AGROINDÚSTRIA FAMILIAR DO OESTE DE SANTA CATARINA
}

\author{
Paula Cristina Slaviero ${ }^{1}$, Liziane Schittler ${ }^{2}$ e Elisandra. Rigo ${ }^{3}$ \\ ${ }^{1}$ Universidade do Estado de Santa Catarina, Departamento de Engenharia de Alimentos e Engenharia \\ Química, Graduada em Engenharia de Alimentos \\ ${ }^{2}$ Universidade do Estado de Santa Catarina, Departamento de Engenharia de Alimentos e Engenharia \\ Química, Doutora em Ciência e Tecnologia Agroindustrial \\ ${ }^{1}$ Universidade do Estado de Santa Catarina, Departamento de Engenharia de Alimentos e Engenharia \\ Química, Doutora em Engenharia de Alimentos \\ E-mail para contato: paula-slaviero@auroraalimentos.com.br
}

\begin{abstract}
RESUMO - A ricota é uma das formas mais simples e econômicas da utilização do soro de leite. Neste contexto, o presente estudo teve como objetivo avaliar a qualidade microbiológica bem como realizar a caracterização físico-química da ricota tipo colonial. Para isto, a ricota produzida por uma agroindústria familiar foi submetida às análises microbiológicas do Número Mais Provável de coliformes totais e coliformes termotolerantes $\left(45^{\circ} \mathrm{C}\right)$, contagem de Staphylococcus coagulase positiva e pesquisa de Salmonella spp., nos tempos zero (24h após processamento) e 30 dias armazenada a 10 ${ }^{\circ} \mathrm{C}$. Foram realizadas contagens de bolores e leveduras, micro-organismos mesófilos aeróbios e bactérias ácido láticas na ricota, obtendo-se valores entre 2,85 e 6,72, 6,37 e 8,24, 3,60 e 7,52 logUFC.g. ${ }^{-1}$, nos tempos zero, 10, 20 e 30 dias de armazenamento, respectivamente. A ricota produzida na agroindústria familiar do Oeste de SC apresenta 0,77\% de cinzas, $49,76 \%$ de umidade, $22,96 \%$ de gordura, $15,59 \%$ de proteína, $0,32 \%$ acidez e $\mathrm{pH}$ de 5,04. Assim, foi possível verificar que a ricota está em conformidade com os padrões microbiológicos estabelecidos pela RDC no 12 de 02/01/2001 (BRASIL, 2001) e apresenta qualidade microbiológica bem como características físico-químicas que conferem a identidade e qualidade do produto.
\end{abstract}

Palavras-chave: Qualidade. Soro de leite. Armazenamento.

DOI: $10.5965 / 24473650412018033$

\section{INTRODUÇÃO}

Segundo estudo realizado por Mattei (2016), o estado de Santa Catarina é conhecido como uma das unidades da federação com maior potencial produtivo leiteiro derivado da agricultura familiar. Com isso, é perfeitamente possível se afirmar que a agricultura familiar é a grande responsável pela atual dinamização do setor leiteiro catarinense. Esta afirmação se ampara na 
Recebido em:

$10 / 09 / 2018$

Aceito em:

$29 / 11 / 2018$

expressiva participação dos estabelecimentos agropecuários familiares no total estadual, tanto em termos numéricos como no volume de ocupações e da produção agropecuária estadual.

Neste sentido, ressalta-se a importância econômica da agricultura familiar no Brasil, uma atividade que, mesmo diante de tantas potencialidades, possui muitas fragilidades, considerando que: se destaca por sua capacidade em termos da produção agrícola, porém ainda é constituída de produção extremamente heterogênea. $O$ termo heterogêneo é utilizado pois inclui desde famílias muito pobres até famílias com grande dotação de recursos. Embora a utilização da categoria "agricultura familiar" seja útil e desejável para fins de formulação de política, é preciso tratá-los como diferentes entre si no que diz respeito à padronização de processos e matérias primas (SOUZA FILHO et al., 2017).

Neste contexto, o soro de leite é um líquido resultante no processo de fabricação do queijo, rico em proteínas e minerais com teores aproximados de $0,8 \%$ a $0,55 \%$, respectivamente. A produção de ricota é uma das formas do processamento do soro de leite (HENING; PIOLA 2013), e pode ser classificada como queijo fresco.

As características físico-químicas da ricota a torna mais propensa ao desenvolvimento microbiano podendo comprometer a vida útil do produto bem como a saúde do consumidor. As boas práticas de fabricação (BPF) representam uma alternativa tecnológica de fácil aplicação para as agroindústrias, trazendo benefícios para a qualidade dos alimentos e evitando perigos de natureza física, química e biológica (FORSYTHE, 2013).

Os micro-organismos bioindicadores que podem ser utilizados para avaliar a qualidade higiênico-sanitária são coliformes termotolerantes $\left(45^{\circ} \mathrm{C}\right)$, Staphylococcus coagulase positiva, e Salmonella spp. (SANTOS et al. 2008).

- Assim, o presente estudo teve como objetivo a caracterização físico-química da ricota produzida na região oeste de Santa Catarina, bem como avaliar a qualidade higiênico-sanitária.

\section{MATERIAL E MÉTODOS}

A ricota tipo colonial, foi produzida em uma agroindústria familiar de Pinhalzinho, SC, acondicionada em embalagem de polietileno de baixa densidade $(0,001 \mathrm{~cm})$ a vácuo, e encaminhada para os laboratórios de Qualidade de Alimentos e Microbiologia de Alimentos do Departamento de Engenharia de Alimentos e Engenharia Química (DEAEQ), da Universidade do Estado de Santa Catarina (UDESC).

Foram avaliadas duas bateladas (1) e (2) de ricotas produzidas em épocas do ano distintas (réplica de amostras) onde as ricotas foram estocadas na temperatura de $10{ }^{\circ} \mathrm{C}$, em câmara de refrigeração, pelo período de 30 dias. As ricotas foram submetidas às análises microbiológicas e físico-químicas, nos tempos de armazenamento de 0,10,20 e 30 dias. Todas as análises foram realizadas em triplicata sendo portando os dados apresentados uma média entre os valores obtidos. Os resultados serão apresentados através do desvio padrão amostral, bem como a diferença significativa $(\mathrm{p}<0,05)$ entre os tempos de armazenamento em relação aos tempos $(0,10,20$ e 30 dias), avaliando as alterações ocorridas durante o período de conservação da ricota e possíveis oscilações de produção. 


\subsection{Qualidade Microbiológica De Ricota Tipo Colonial Comercializada No Oeste De Santa Catarina}

Para avaliar a qualidade microbiológica da ricota, utilizou-se os métodos descritos na Instrução Normativa $\mathrm{n}^{\circ}$ 62, de 26 de agosto de 2003, do Ministério da Agricultura, Pecuária e Abastecimento (BRASIL, 2003).

As ricotas foram submetidas às análises do Número Mais Provável (NMP) de coliformes à 36 ${ }^{\circ} \mathrm{C}$ e à $45^{\circ} \mathrm{C}$, contagem de Staphylococcus coagulase positiva e pesquisa de Salmonella spp., nos tempos zero e no $30^{\circ}$ dia de armazenamento a temperatura de $10^{\circ} \mathrm{C}$. Nos tempos, zero, 10,20 e 30 dias de armazenamento foram realizadas contagem de bolores e leveduras, contagem de microorganismos mesófilos aeróbios e contagem de bactérias ácido lácticas (BAL) nas ricotas.

\subsection{Caracterização Físico-química De Ricota Tipo Colonial Comercializada No Oeste De Santa Catarina}

Foram determinadas cinzas, umidade, gordura, proteína, $\mathrm{pH}$ e acidez em percentual de ácido láctico (\% A.L) na ricota durante o período de armazenamento utilizando métodos Analíticos Oficiais descritos na IN ${ }^{\circ} 68$ de 12/12/2006 do Ministério da Agricultura, Pecuária e Abastecimento (BRASIL, 2006).

\subsection{Análise Estatística}

Os resultados obtidos nas análises microbiológicas e físico-químicas foram submetidos à análise de variância (ANOVA), seguida do teste de Tukey, com nível de 95\% de confiabilidade. Utilizou-se o software STATISTICA® versão 10.0 (StatSoft Inc®, USA).

\section{RESULTADOS E DISCUSSÃO}

\subsection{Qualidade Microbiológica De Ricota De Ricota Tipo Colonial Comercializada No Oeste De Santa Catarina}

Na Tabela 1, estão apresentados os resultados obtidos nas análises microbiológicas referentes aos indicadores de qualidade higiênico-sanitário nas ricotas.

Dentre os micro-organismos avaliados estão as bactérias do grupo coliforme, são consideradas como os principais agentes causadores de contaminação associados à deterioração de queijos, causando fermentações anormais e estufamento precoce dos produtos (OLIVEIRA et al., 1998; ALMEIDA; FRANCO, 2003). Incluem todos os bacilos gram-negativos, aeróbios e anaeróbios facultativos, que não formam esporos e são capazes de fermentar a lactose com produção de gás, em 24 - 48 horas, a $35^{\circ} \mathrm{C}$ (coliformes totais) (SILVA et al., 2001).

A média do NMP de coliformes à $36{ }^{\circ} \mathrm{C}$ na ricota variou entre 2,51 e 3,21 log NMP g ${ }^{-1}$, nos tempos zero e 30 dias de armazenamento (Tabela 1). Valores superiores foram relatados por Cereser et al. (2011), ao avaliarem duas marcas comerciais de ricota, comercializadas no estado de São Paulo, 
Recebido em:

$10 / 09 / 2018$

Aceito em:

$29 / 11 / 2018$

e obtiveram contagens de coliformes à $36{ }^{\circ} \mathrm{C}$, que variaram entre 5,04 e 7,04 log NMP g-1. A Resolução RDC no 12/2001 do Ministério, não estabelece padrão para coliformes à $36{ }^{\circ} \mathrm{C}$ (BRASIL, 2001). Este resultado demonstra que a ricota produzida na agroindústria familiar do Oeste de SC foi elaborada com matéria-prima de qualidade e com boas práticas de fabricação.

Já os coliformes termotolerantes (fecais), compreendem o grupo de bactérias originárias do trato gastrointestinal de humanos e de outros animais homeotérmicos. Também fazem parte os microorganismos não fecais, que podem ser destruídos pela pasteurização. Desta maneira, a presença de coliformes fecais em alimentos processados, como a ricota, é indicação útil de contaminação póssanitização ou pós-processo, evidenciando práticas de higiene e sanitização aquém dos padrões requeridos para o processamento de alimentos (SILVA et al., 2001).

A ricota, produzida pela agroindústria familiar do Oeste de Santa Catarina, apresentou-se de acordo com o padrão estabelecido pela RDC no 12/2001, de no máximo 2,70 log NMP g ${ }^{-1}$, para coliformes à $45{ }^{\circ} \mathrm{C}$ (BRASIL, 2001). A média do NMP de coliformes à $45{ }^{\circ} \mathrm{C}$ (fecais) variou entre 1,29 e 1,57 log NMP g ${ }^{-1}$ nas ricotas, durante os tempos zero e 30 dias de armazenamento (Tabela 1).

Resultados inferiores foram relatados por Lucas e Centenaro (2010), onde obtiveram < $1 \log$ UFC $\mathrm{g}^{-1} \mathrm{e}<0,3 \mathrm{NMP} \mathrm{g}^{-1}$ de coliformes à $45^{\circ} \mathrm{C}$, em ricotas adicionadas de fibras e ricota cremosa, respectivamente.

A obtenção higiênica do leite para produção de derivados é um fator crucial para uma boa qualidade microbiológica, porém, apesar da pasteurização diminuir a população microbiana no leite, algumas toxinas, como a enterotoxina estafilocócica não são inativadas, podendo causar intoxicações alimentares (FOX, 1993).

A média das contagens de Staphylococcus coagulase positiva foi de $<2,0$ log UFC g g $^{-1}$ nos tempos zero e 30 dias de armazenamento (Tabela 1). De acordo com a legislação, a ricota produzida na agroindústria familiar, está dentro do padrão estabelecidos de no máximo de $2,70 \log \mathrm{UFC} \mathrm{g}^{-1} \mathrm{de}$ Staphylococcus coagulase positiva (BRASIL, 2001).

Resultados iguais foram descritos por Hening e Piola (2013) e Ribeiro et al. (2005), onde obtiveram contagens de Staphylococcus coagulase positiva de $<2,0 \log \mathrm{UFC} \mathrm{g}^{-1}$ em ricota saborizada adicionada de oligofrutose e em ricota cremosa, ambas produzidas em laboratório.

Não foi identificada a presença de Salmonella spp. em 25 g de ricota analisada, nos tempos zero e 30 dias de armazenamento (Tabela 1). Logo, a ricota produzida na agroindústria familiar do Oeste de SC, encontrou-se de acordo com a legislação 12/2001 (BRASIL, 2001) e 146/1996, que determina a ausência de Salmonella spp. em 25 gramas (BRASIL, 1996).

Contagens elevadas de bolores e leveduras, em alimentos, indicam que a produção ocorreu sob condições de higiene insatisfatórias. Além disso, quando presentes em queijos, por exemplo, esses micro-organismos são os principais responsáveis pela deterioração do produto (FEITOSA et al., 2003), o que ressalta a importância de seu controle.

Observa-se na Tabela 1, que a média das contagens de bolores e leveduras nas ricotas variaram entre 2,85 e 6,72 log UFC g ${ }^{-1}$, durante os 30 dias de armazenamento, a $10{ }^{\circ} \mathrm{C}$. Houve diferença estatística $(\mathrm{p}<0,05)$ nas contagens de bolores e leveduras entre o tempo zero e os tempos 10, 20 e 30 dias de armazenamento. A Portaria no 146/1996 do Ministério da Agricultura e Pecuária, refere-se aos padrões de identidade e qualidade dos produtos lácteos, e estabelece que o limite máximo é de 3,70 $\log \mathrm{UFC} \mathrm{g}^{-1}$, para bolores e leveduras. Já a legislação RDC 12/2001 não estabelece padrão para bolores e leveduras. Nesse sentido, levando em consideração a Portaria $n^{\circ}$ 146/1996, somente no 
Recebido em:

$10 / 09 / 2018$

Aceito em:

$29 / 11 / 2018$

tempo zero, ou seja, logo após a elaboração da ricota, os níveis de bolores e leveduras encontraram-se de acordo com a legislação.

Cereser et al. (2011), relataram contagens de bolores e leveduras entre 4 e 6 log UFC g gm $^{-1}$ ricota comercializada em supermercados do estado de São Paulo.

Embora em nossa legislação não existam parâmetros regulamentados para micro-organismos mesófilos, a presença em níveis elevados em alimentos, pode indicar a presença de bactérias patogênicas.

As contagens de micro-organismos mesófilos aeróbios variaram entre 6,37 e 8,24 log UFC g $\mathrm{g}^{-1}$ (Tabela 1). Houve diferença significativa $(\mathrm{p}<0,05)$ nas contagens no decorrer do tempo de armazenamento. Os micro-organismos mesófilos aeróbios podem ser utilizados como indicadores de qualidade, assim, os resultados dessa pesquisa mostram que 20 dias seria o tempo ideal para consumo do produto, pois após esse tempo a população microbiana de mesófilos aeróbios pode oferecer risco a saúde do consumidor. Segundo Franco e Langraft (1996), contagens acima de 8 log UFC g ${ }^{-1}$ revelam que o alimento pode ter sofrido alterações organolépticas, e também oferecer riscos à saúde do consumidor.

A ricota apresenta condições propícias para a multiplicação de micro-organismos, sejam patogênicos ou deteriorantes. Isso se deve, principalmente, à alta umidade e à disponibilidade de nutrientes, como sais minerais e lactose, o que compromete a qualidade do produto e sua vida de útil (MAIA et al., 2004).

As bactérias ácido láticas (BAL) apresentam um papel importantíssimo como culturas iniciadoras, porém em alguns derivados de leites, como a ricota, estas bactérias precisam ser controladas pois influem diretamente sobre o $\mathrm{pH}$ e acidez do produto. De acordo com Cavalcanti (2014), o principal metabólico bacteriano produzido pelas BAL é o ácido láctico, proveniente da utilização da lactose pelas bactérias e que ocasiona redução do pH em alimentos.

Observou-se (Tabela 1), que a média das contagens de BAL nas ricotas variaram entre 1,95 e 7,44 $\log$ UFC $\mathrm{g}^{-1}$ durante os 30 dias de armazenamento. Além disso, não houve diferença significativa nas contagens de BAL entre os tempos zero, 10, 20 e 30 dias de armazenamento.

Dagostini (2011), em sua avaliação de características microbiológicos e físico-químicos, no queijo minas frescal elaborado a partir de leite carbonatado, obteve contagens de BAL de 2,49 e 7,22 $\log$ UFC $\mathrm{g}^{-1}$, no tempo zero e após vinte dias de armazenamento, respectivamente. Já Sangaletti (2007), ao analisar o crescimento de BAL em três lotes de queijos Minas Frescal comerciais, observou uma média de contagens de 7,31 \pm 0,80 $\log \mathrm{UFC} \mathrm{g}^{-1}$, após 20 dias de armazenamento. 
Recebido em:

$10 / 09 / 2018$

Aceito em:

$29 / 11 / 2018$

Tabela 1 - Análises de indicadores higiênicos sanitários em ricota durante os 30 dias de armazenamento, a 10 ${ }^{\circ} \mathrm{C}$.

\begin{tabular}{|c|c|c|c|c|}
\hline \multirow[t]{2}{*}{ Análise } & \multicolumn{4}{|c|}{ Tempo (dias) } \\
\hline & 0 & 10 & 20 & 30 \\
\hline Coliformes à $36^{\circ} \mathrm{C}\left(\log \mathrm{NMP} \mathrm{g}^{-1}\right)$ & $2,51 \pm 1,24$ & - & - & $3,21 \pm 0,24$ \\
\hline Coliformes à $45^{\circ} \mathrm{C}\left(\log \mathrm{NMP} \mathrm{g}^{-1}\right)$ & $1,29 \pm 0,48$ & - & - & $1,57 \pm 0,86$ \\
\hline Staphylococcus c. p (log UFC g $\left.{ }^{-1}\right)$ & $<2,00 \pm 0,00$ & - & - & $<2,00 \pm 0,00$ \\
\hline Pesquisa de Salmonella spp. & Ausência & - & - & Ausência \\
\hline Bolores e Leveduras (log UFC g $\left.{ }^{-1}\right)$ & $2,85 \pm 0,18^{\mathrm{A}}$ & $5,75 \pm 0,15^{\text {В }}$ & $5,76 \pm 1,07^{\mathrm{B}}$ & $6,72 \pm 0,53^{\text {В }}$ \\
\hline Mesófilos aeróbios ( $\log \mathrm{UFC}^{-1}$ ) & $5,38 \pm 1,82^{\mathrm{A}}$ & $7,61 \pm 0,62^{\mathrm{A}}$ & $8,13 \pm 0,18^{A}$ & $8,11 \pm 0,50^{\mathrm{A}}$ \\
\hline Bactérias ácido lácticas $\left(\log \mathrm{UFC}^{-1}\right)$ & $1,95 \pm 2,76^{\mathrm{A}}$ & $6,30 \pm 1,39^{\mathrm{A}}$ & $6,63 \pm 0,45^{\mathrm{A}}$ & $7,44 \pm 0,38^{\mathrm{A}}$ \\
\hline
\end{tabular}

${ }^{\mathrm{AB}}$ Letras maiúsculas diferentes na mesma linha indicam diferença estatística, pelo teste de Tukey $(\mathrm{p}<0,05)$ entre os tempos.

Fonte: elaborado pelo autor (2018)

\subsection{Caracterização Físico-Química De Ricota Tipo Colonial Comercializada No Oeste De Santa Catarina}

Os resultados das análises de cinzas, umidade, gordura, proteína, $\mathrm{pH}$ e acidez estão representados nas Figuras 1, 2 e 3, sendo expressa as médias entre as bateladas (1) e (2) em um mesmo tempo de armazenamento. Em relação aos valores de cinzas, percebeu-se um elevado desvio padrão amostral devido a diferença da composição de minerais do leite produzido na primeira batelada (1) em relação a segunda batelada (2). Quando avaliado a diferença significativa $(\mathrm{p}<0,05)$ entre os tempos de armazenamento, percebe-se que os valores não diferiram significativamente ( $\mathrm{p}<$ $0,05)$.

No trabalho de Madalozzo (2010), que caracterizou ricotas via espectroscopia em infravermelho e calibração multivariada, encontrou-se teores de cinzas de 0,68 a 2,64\%. Valores próximos aos encontrados neste trabalho que estão exemplificados na Figura 1.

Para os dados de umidade, os desvios padrões foram elevados entre as bateladas (1) e (2) em cada tempo de análise, tendo uma variação de $15,44 \%$ entre as bateladas no tempo inicial. Esta variação pode ter ocorrido devido a agroindústria não possuir tempo determinado para o dessoramento, bem como usar sistema de prensa manual. Considerando a mesma batelada e diferentes tempos de análise, percebe-se uma diminuição da umidade com o aumento do tempo de armazenamento pela exsudação de líquidos, com essa variação houve diferença significativa ( $\mathrm{p}<$ 0,05 ) de umidade nos tempos zero e dez dias em relação aos tempos de vinte e trinta dias (ITAL, 2004).

A ricota é classificada pela legislação como queijos alta umidade (> 55\%) (BRASIL, 1996). Os resultados referentes a média entre as bateladas ficaram abaixo do preconizado pela legislação 
Recebido em:

$10 / 09 / 2018$

Aceito em:

$29 / 11 / 2018$

variando de $47,38 \%$ até $51,63 \%$. No trabalho de Cunha (2014), foi observado que a análise de umidade de uma determinada marca de ricota Light indicou valores fora da legislação por apresentarem valores inferiores a 55\%, variando de 44,55 a 59,68\%.

Os resultados das análises de cinzas e umidade, ao longo do tempo de armazenamento, podem ser observadas na Figura 1. A umidade decresceu ao longo do tempo devido à perda para o meio externo (perda de vácuo da embalagem). A perda de vácuo acontece por alguns fatores que podem estar relacionados a deficiência do equipamento de extração de vácuo, selagem incorreta ou até mesmo defeitos na embalagem.

Em relação aos valores de gordura, esses podem ser visualizados na Figura 2. Segundo a Portaria $\mathrm{n}^{\circ} 146$ de 07 de março de 1996, o teor máximo de gordura estipulado é 24,9\% para queijos magros, nesse sentido, todas as médias entre as duas bateladas encontraram-se menores do que o estipulado pela legislação (BRASIL, 1996) e não apresentaram diferença significativa $(\mathrm{p}<0,05)$ entre os tempos de armazenamento. Esper (2006), avaliou a qualidade de ricotas comercializadas no município de Campinas - SP, e encontrou valores de gordura que variaram de 5,89 à 24,82\%.

Os dados referentes à proteína se comportaram da mesma forma que a gordura, não apresentando diferença significativa $(\mathrm{p}<0,05)$ entre os tempos de armazenamento, como observa-se na Figura 2. Um estudo de Madalozzo (2010) que analisou 19 amostras de ricota, encontrou valores de proteína que variou de 8,69 a 17,97\%, corroborando com os resultados encontrados no presente trabalho, descritos na Tabela 1.

A gordura e proteína são consideradas macromoléculas e foram correlacionadas na Figura 2 com o tempo de armazenamento.

Figura 1 - Relação entre umidade e cinzas ao longo do tempo de armazenamento.

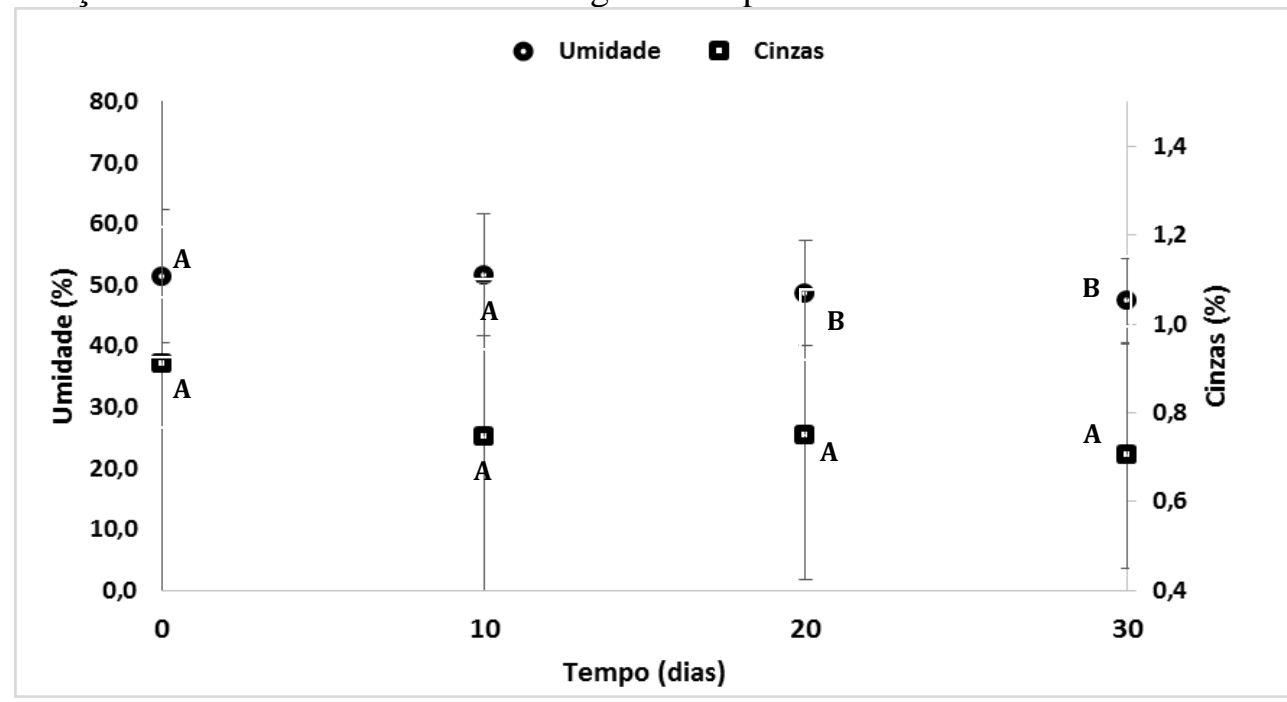

${ }^{\mathrm{AB}}$ Letras maiúsculas diferentes no mesmo marcador indicam diferença estatística pelo teste de Tukey (p < $0,05)$ entre os tempos de armazenamento.

Fonte: elaborado pelo autor (2018) 


\section{Recebido em:}

$10 / 09 / 2018$

Aceito em:

$29 / 11 / 2018$

Figura 2 - Relação das macromoléculas gordura e proteína ao longo do tempo de armazenamento.

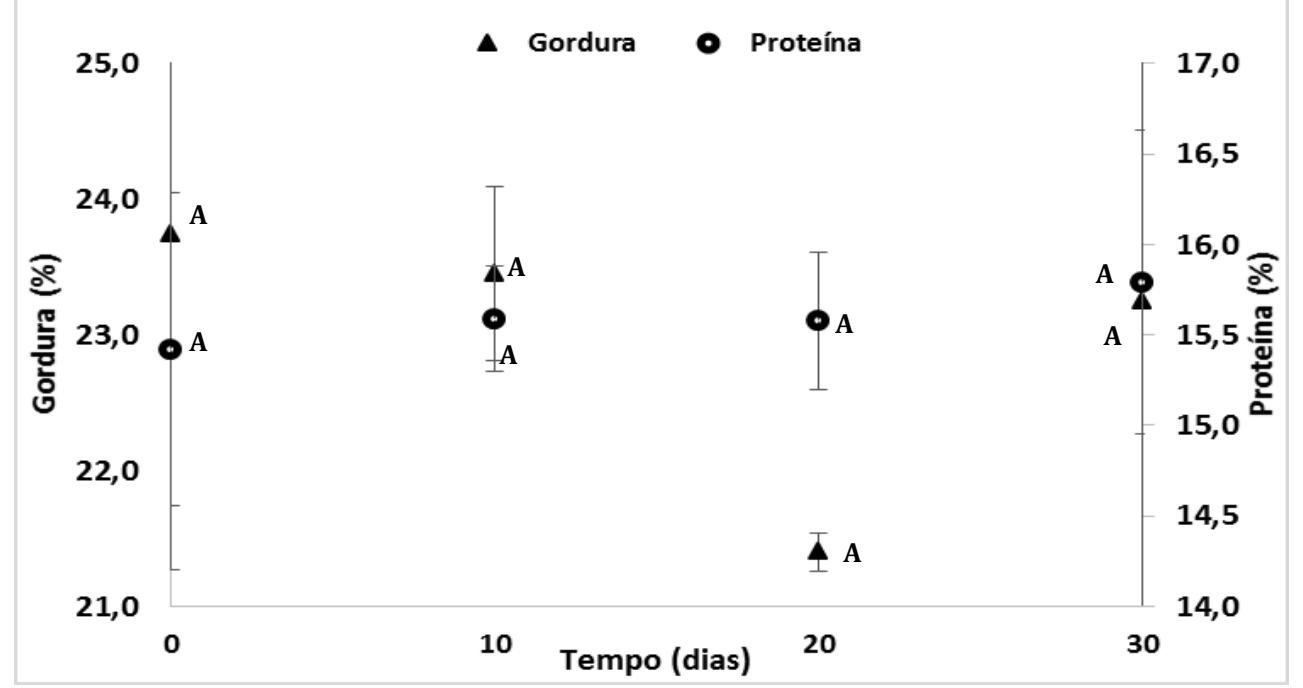

${ }^{\mathrm{AB}}$ Letras maiúsculas diferentes no mesmo marcador indicam diferença estatística pelo teste de Tukey $(\mathrm{p}<$ $0,05)$ entre os tempos de armazenamento.

Fonte: elaborado pelo autor (2018)

Na Figura 3, acidez e pH encontram-se correlacionados com o tempo de armazenamento, percebe-se um aumento de acidez a medida que o $\mathrm{pH}$ diminui, variáveis estas que podem ser correlacionadas inversamente.

Os valores de $\mathrm{pH}$ apresentaram-se com desvio padrão amostral elevado possivelmente devido a variabilidade da matéria-prima utilizada. Somente nos tempos de armazenamento de vinte e trinta dias os resultados não apresentaram diferença significativa ( $\mathrm{p}<0,05)$. Lacerda et al. (2005), observou valores de $\mathrm{pH}$ que variaram de 4,55 a 6,44 em amostras de ricota comercializadas no município de Itapetinga - BA.

Os dados de acidez foram expressos em porcentagem de ácido láctico (\% A.L), como mostra a Figura 3, percebe-se que com a diminuição do $\mathrm{pH}$ se tem um aumento da acidez. Os resultados de acidez diferiram significativamente $(\mathrm{p}<0,05)$ entre todos os tempos de armazenamento. Resultados encontrados por Cunha (2014), evidenciaram índices de acidez de 0,20 à 1,38 \% Á.L em ricotas tradicional, light e orgânica, próximos ao encontrado neste trabalho. 
Recebido em:

$10 / 09 / 2018$

Aceito em:

$29 / 11 / 2018$

Figura 3 - Relação entre acidez e pH ao longo do tempo de armazenamento.

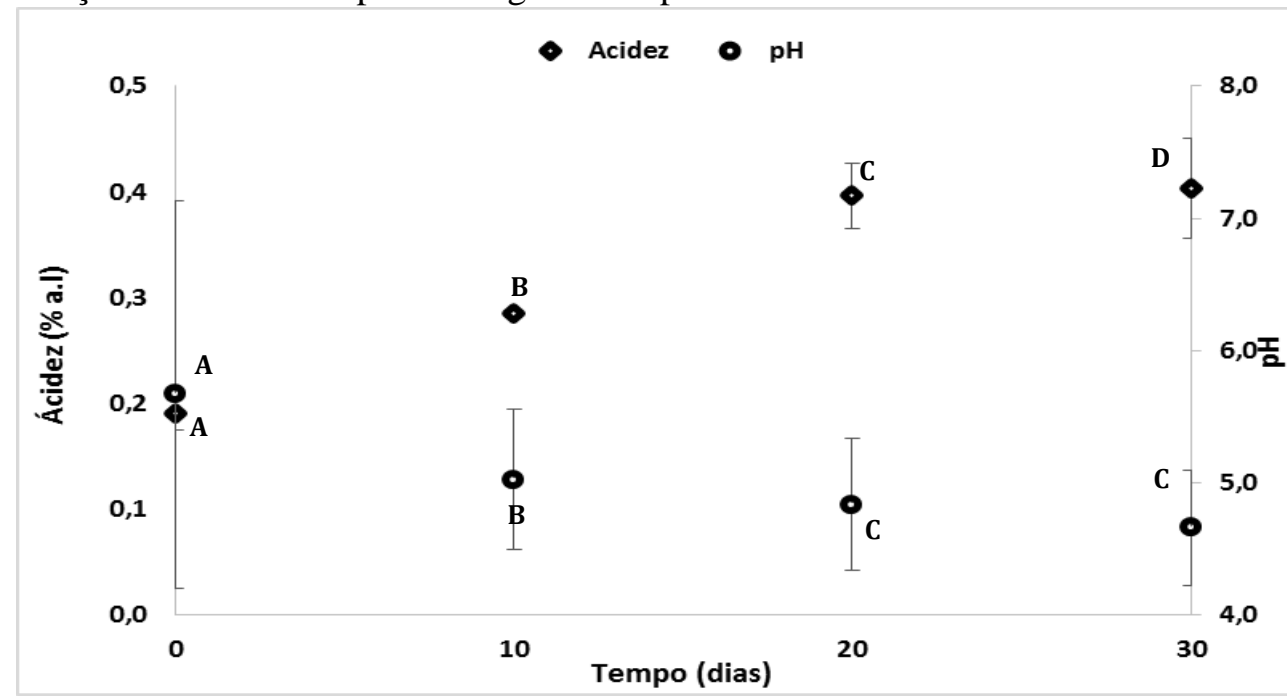

${ }^{\mathrm{AB}}$ Letras maiúsculas diferentes no mesmo marcador indicam diferença estatística pelo teste de Tukey ( $\mathrm{p}<$ $0,05)$ entre os tempos de armazenamento.

Fonte: elaborado pelo autor (2018)

\section{CONCLUSÃO}

A ricota do tipo colonial, produzida em uma agroindústria familiar do Oeste de Santa Catarina, apresentou-se com qualidade microbiológica pois atendeu os padrões microbiológicos estabelecidos pelas legislações vigentes. Quanto à caracterização físico-química somente os valores de umidade ficaram abaixo do estipulado pela legislação para queijos úmidos (> 55\%), ressaltando que os demais componentes avaliados conferem com o que está preconizado na legislação.

\section{REFERÊNCIAS}

ALMEIDA, P.M.P.; FRANCO, R.M. Avaliação bacteriológica de queijo tipo Minas Frescal com pesquisa de patógenos importantes à saúde pública: Staphylococcus aureus, Salmonella sp. e Coliformes Fecais. Higiene Alimentar, [s.l.], v.17, n.11, p.79-85, 2003.

BRASIL. Ministério da Agricultura, Pecuária e Abastecimento. Instrução Normativa nº 68, 12 de dezembro de 2006. Oficializa os Métodos Analíticos Oficiais Físico-Químicos, para Controle de Leite e Produtos Lácteos. Diário oficial da união, Brasília, DF, 14 de dezembro de 2006.

BRASIL. Ministério da Agricultura, Pecuária e Abastecimento. Instrução Normativa Nº 62, de 26 de agosto de 2003. Oficializa os Métodos Analíticos Oficiais para Análises Microbiológicas para Controle de Produtos de Origem Animal e Água. Diário Oficial da União, Brasília, DF, 18 setembro 2003. 
BRASIL. Ministério da Agricultura, Pecuária e Abastecimento. Portaria n 146, de 23 de Março de 1996. Aprova os Regulamentos Técnicos de Identidade e Qualidade dos Produtos Lácteos. Diário Oficial da União, Brasília, DF, 11 março 1996.

BRASIL. Ministério da Saúde. Resolução no. 12, de 2 de janeiro de 2001. Aprova Regulamento Técnico Sobre os Padrões Microbiológicos para Alimentos. Art. 4a. Diário Oficial da União, Brasília, DF, 10 janeiro 2001.

CAVALCANTI, F. B. Avaliação microbiológica do queijo "tipo ricota" comercializados em supermercados de Campina Grande PB. 2014. 29 f. TCC (Graduação em Química Industrial), Universidade Estadual da Paraíba, Centro de Ciências e Tecnologia, Campina Grande, Paraíba.

CERESER, N.D.; JÚNIOR, O.D.R.; MARCHI P.G.F de; SOUZA, V de; CARDOZO, M.V.; MARTINELI, T.M. Avaliação da qualidade microbiológica da ricota comercializada em supermercados do estado de São Paulo. Ciência Animal Brasil. Goiânia, v. 12, n. 1, p. 149-155, jan./mar. 2011.

CUNHA, E. de O. Análise comparativa da qualidade nutricional de ricotas tradicional, light e orgânica vendidas em João Pessoa. Trabalho de conclusão (graduação), Departamento de Nutrição da Universidade Federal da Paraíba - UFP. João Pessoa, 2014.

DAGOSTIN, J. L. A. Avaliação de atributos microbiológicos e físico-químicos de queijo minas frescal elaborado a partir de leite carbonatado. Dissertação (mestrado) - Universidade Federal do Paraná, Setor de Tecnologia, Programa de Pós-Graduação em Tecnologia de Alimentos. Curitiba, 2011.

ESPER, M.R.L. Diagnóstico da qualidade de ricotas comercializadas no município de Campinas-SP. Dissertação. Mestrado em Engenharia de Alimentos - Universidade Estadual de Campinas - FEA, Campinas-SP, 2006.

FEITOSA, T.; BORGES M. F.; NASSU, R. T.; AZEVEDO, E. H. F.; MUNIZ, C. M. Pesquisa de Salmonella sp., Listeria sp. e microrganismos indicadores higiênico-sanitários em queijos produzidos no estado do Rio Grande do Norte. Ciência e Tecnologia de Alimentos, [s.l], v. 23, n. 3, p. 162-165, 2003.

FORSYTHE, S.T. Microbiologia da segurança de alimentos. 2 ed. Porto Alegre: Artmed, 2013.

FOX, P. F. Cheese: chemistry, physics and microbiology. London, Chapman London, Chapman e Hall, 463 p., 1993. Hall, 463 p., 1993.

FRANCO, B. D. G. M; LANDGRAF, M. Microbiologia dos alimentos. São Paulo: Atheneu, 1996. 
HENING, B.; PIOLA, R. de L. Desenvolvimento de ricota saborizada adicionada de oligofrutose. 2013. Trabalho de Conclusão de Curso (Graduação), Curso Superior de Tecnologia em Alimentos Universidade Tecnológica Federal do Paraná - UTFPR. Francisco Beltrão, 2013.

ITAL. Parecer técnico sobre embalagens plásticas - Relatório CETEA A028/04 resumo do relatório final. Disponível em: <http://www.plastivida.org.br/images/temas/CETEA_parecertecnico-embalagens-plasticas_resumo-final.pdf >. Acesso 08 nov. 2016.

LACERDA, E.C.Q.; PIGNATA, C.M.; SAMPAIO, V.S.; PEREIRA, R.G.; PIGNATA, M.C.; REIS, R.C. Qualidade Físico-Química de Ricota Comercializada no Município de Itapetinga Bahia, 2005.

MAIA, S. R.; FERREIRA, A. C.; ABREU, L. R. Uso do açafrão (Curcuma longal) na redução da Escherichia coli e Enterobacter aerogenes em ricota. Ciência e Agrotecnologia, v. 28, n. 2, p. 358365, 2004.

MADALOZZO, E.S. Caracterização Físico-Química de Ricotas via Espectroscopia no Infravermelho e Métodos de Calibração Multivariada. 2010. Dissertação (Mestrado em Ciência e tecnologia em Alimentos) - Universidade Estadual de Ponta Grossa, Ponta Grossa, PR.

MATTEI, L. A importância do sistema familiar de produção no estado de Santa Catarina. Revista NECAT. Ano 5, n. 9 Jan-Jun de 2016.

MUNDO MICROSCÓPICO. Microbiologia de alimentos: Fatores que influenciam na multiplicação microbiana. Disponível em: <

https://mundomicroscopicoo.wordpress.com/2013/06/05/fatores-que-influenciam-na-multiplicacaomicrorbiana/ >. Acesso em 08 nov. 2016.

OLIVEIRA, C.A.F.; MORENO, J.F.G.; MESTIERI, L.; GERMANO, P.M.L. Características físicoquímicas e microbiológicas de queijos Minas Frescal e Mussarela, produzidos em algumas fábricas de laticínios do Estado de São Paulo. Higiene Alimentar, v.12, n.55, p.31-35, 1998.

RIBEIRO, A.C.; MARQUES, S.C.; SODRÉ, A de F.; ABREU, L.R de; PICCOLI R.H. Controle Microbiológico da Vida de prateleira de Ricota Cremosa. Ciências agrotecnologicas V. 29, p. 113117, Lavras, 2005.

SANGALETTI, N. Estudo da vida útil do queijo Minas Frescal disponível no mercado. $80 \mathrm{f}$. Dissertação (Mestrado em Ciência e Tecnologia dos Alimentos) - Escola Superior de Agricultura Luiz Queiroz, Universidade de São Paulo, Piracicaba, 2007.

SANTOS, V.A.Q.; CARVALHO, C.C.P.; GONÇALVES, T.M.V.; HOFFMANN F.L. Controle microbiano em linha de produção de queijos Minas Frescal e Ricota. Revista portuguesa de ciências veterinárias. São José do Rio Preto, v.103 p. 219-227. 2008. 
SILVA, N.; JUNQUEIRA, V.C.A.; SILVEIRA, N.F.A.; TANIWAKI, M.H.; SANTOS, R.F.S.; GOMES, R.A.R. Manual de métodos de análise microbiológica de alimentos e água. 4.ed. São Paulo: Varela. 614p. , 2010.

SOUZA FILHO, H. M.; BUAINAIN, A.M.; GUANZIROLI, C.; BATALHA, M.O. Agricultura familiar e tecnologia no Brasil: características, desafios e obstáculos. 2017. Disponível em: <www.sober.org.br/palestra/12/09O442.pdf>. Acesso em: 28 ago. 2018. 